\title{
The data analysis of college campus media WeChat public platform --take "voice of NCIST" as an example
}

\author{
Liu Dongmei, a , Zhang Junsong ${ }^{2, b}$ \\ ${ }^{1}$ North China Institute of Science and Technology, CHINA \\ ${ }^{2}$ North China Institute of Science and Technology, CHINA \\ a,bliudongmei51020@sina.com
}

Keywords: college, WeChat public platform, campus media, publicity

\begin{abstract}
With the rapid development of Internet, WeChat public platform has became a fresh battle field in ideology. Being an important force on promoting advanced culture and core values of socialism, with the aid of WeChat public platform, college are required to enlarge public opinion fields and firmly seize initiative on ideology instruction, especially campus media, school organizations, Youth League Committee, alumni association and student union. The WeChat of "Voice of NCIST" has more than 30000 users in the past two years and set up a model to campus media. From the aspects of orientation and team, the writer attempts to provide measures and suggestions to college WeChat public platform.
\end{abstract}

\section{1、The Introduction}

Tencent launched WeChat in January 2011. WeChat is APP instant communication tools, which run on intelligent terminals. Users can add friends and follow the public platform to appreciate wonderful content.As in the first quarter of 2015,the national WeChat public account has amounted to 13 million and still grows at 15000 per day. [1]More than 10 billion people have launched account on WeChat and active users reach 4.68 billion monthly, which means that more than $30 \%$ of the population contact with others use WeChat in China.

\section{2、The WeChat Platform}

Tencent: The Data Report of WeChat Platform In 2015 points out that WeChat users group is very young,18-35 years old people are the main users, which is up to $86.2 \%$ (Table1), including $19.7 \%$ of students. WeChat has gradually become a part of people's lives,the everyday use above 10 times up to 55.2\%(Table 2). [2]In the current campus, WeChat is changing the college students' way of thinking, life and socialize.

Table 1 The age distribution of we-chat users

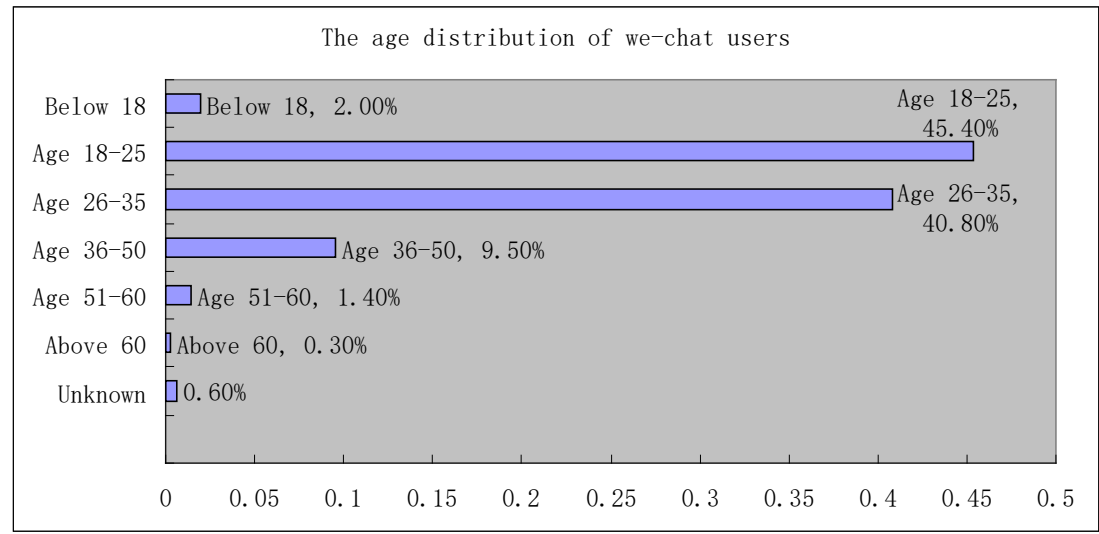


Table 2 The average time for everyday use

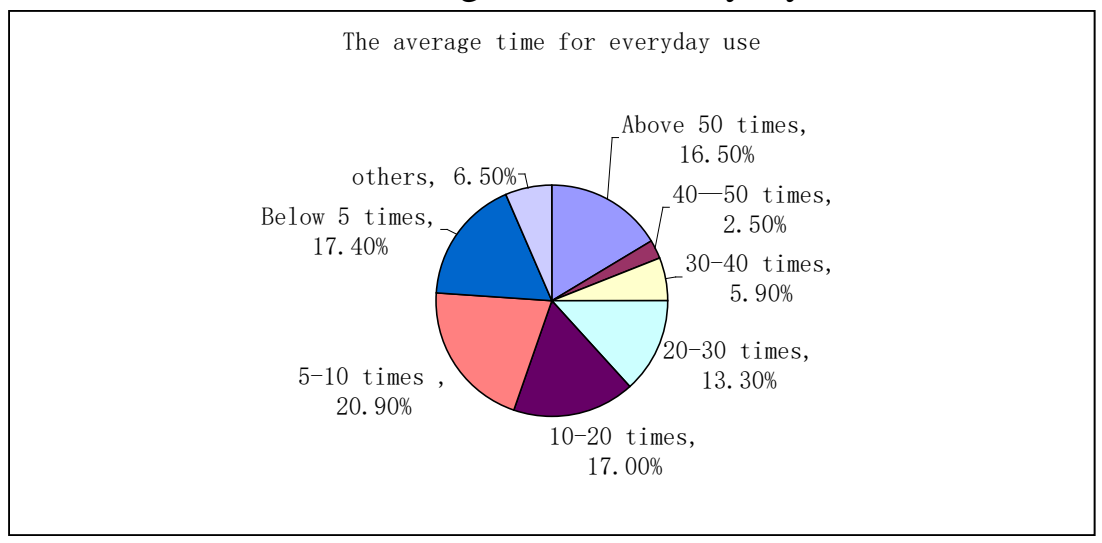

\section{3、Analysis on advantages of college WeChat public platform}

\subsection{Pertinence}

Under the certain communication circumstance of universities, the target audience is formed by teachers and students, so Wechat platform publicity needs to select its materials which satisfies the needs of this group. [3]

\subsection{Assistance}

School news is one of the most important sections for Wechat platform publicity, activities and e vents taking place around students easily attract their attention and are also of assistance for their da ily life. For example, notices or school activities enable teachers and students to take part in time.

\subsection{Interests}

Because working staff and audience of Wechat public platforms tend to be at a young age, meth ods and materials for the publicity should break the rules of being cliché and stiff, and fit the tastes of young people instead. Therefore, Wechat publicity tries to bring more fun to its audience through both the titles and main bodies of the articles. There are different ways for publicity as well, besides notices with graphics and texts, there are also notices with audios, videos, ect.

\subsection{Inspiration}

Wechat public platforms often publish news on research results, outstanding works and awards o $\mathrm{f}$ the school teachers and students, which inspires the spirit and morale on carrying on academic res earch of the school teachers and students, and also strengthens their sense of identity and cohesion.

\section{The data analysis of “voice of NCIST” WeChat}

\subsection{Basic information}

The WeChat of "Voice of NCIST" was registered on Nov.7th,2013,this WeChat has 10000 users after one year of development and completed official certification on June 25th, 2015. As the subscription, this WeChat releases one period per day, including a number of graphics and text. The WeChat of "Voice of NCIST" has more than 30000 users in the past two years and set up a model to campus media.

The users of WeChat of "Voice of NCIST" probably divide into four groups: students, alumnus, parents of students and other college students. Users throughout the country,including 9545 people in hebei province (ranks first), 7319 people in the city of Langfang (ranks first). In addition to the $3.74 \%$ of users do not have released their own gender, the rest of the users accounted for $49.98 \%$ male and $46.29 \%$ female.

\subsection{Achievement}

On Nov.6th,2015, the capital college media alliance announced the capital college campus media WeChat public platform ranking list, The WeChat of "Voice of NCIST" article counts list ranked second, WCI list is located in the 11th. As a newly established university,which has only 16000 students, North China Institute of Science and Technology's campus media WeChat public platform 
has 30000 users, overall readership of the WeChat is more than some other key universities, it is not easy.

\subsubsection{Accurate orientation}

Use and gratifications approach reminds us that the purpose of the audience to use the media is not the same, and the audience has the right to control in most cases. The theory guides us to pay more attention to the audience, and make meet the needs of the audience as a basic standard to measure the effect of communication.The WeChat of "Voice of NCIST" is in accordance with the needs of the audience to choose content and releases at prime time, [4]in other words $11 \mathrm{pm}$ or so.

In order to establish a brand,the WeChat of " Voice of NCIST" set up two special columns"secrets in tree hole" and "campus evening news", the content is all original. "secrets in tree hole" is the voice of the users to reveal themselves, "campus evening news"is news of the university that day.

\subsubsection{Teamwork}

The WeChat public platform want to run efficiently,there must be an excellent professional team. Team members can grasp the social and campus dynamics in a timely manner,have rich knowledge and broad vision, understand the characteristics and the discourse system of college students, have good information integration and technical support capabilities. [5]

The WeChat of " Voice of NCIST" maintains the daily operation by the nine students, more than 30 other students in the team to interview the news or provide appropriate photos. This team has very strong sense of responsibility, persists in the daily release of information for two years and they spent a lot of time and energy.They have held more than 20 times "Online voting”and" scanning gift", to improve the influence of the WeChat. Users are not easy to maintain through the activities,so the WeChat must have wonderful content to retain them.

Nov.25th,2015 to Nov. 29th, The WeChat of " Voice of NCIST" has a " campus dormitory culture festival" voting activity.Nov. 26th, the new rising follow number of the WeChat is 4503(Table 3), and the number of unfollow is 894 (Table 4)that day.

Table 3 The new rising follow number in the WeChat of " Voice of NCIST"

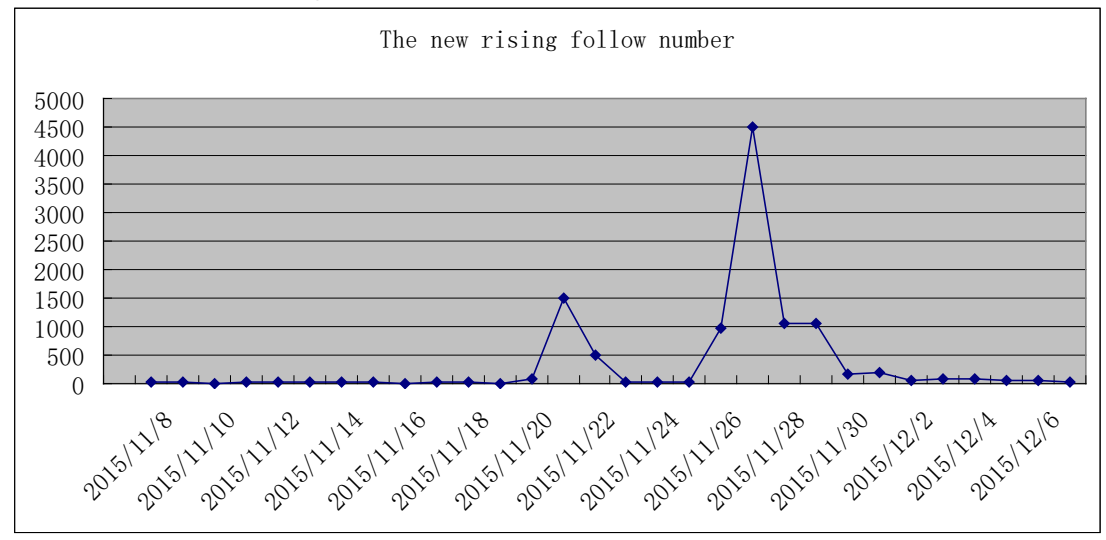

Table 4 The number of unfollow in the WeChat of " Voice of NCIST"

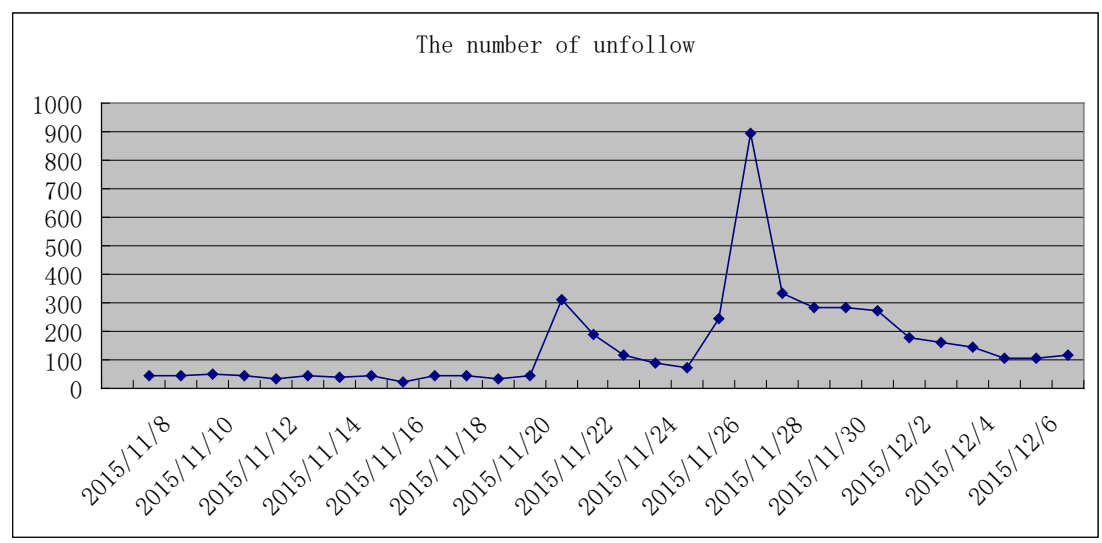




\section{Summary}

This paper analyzes the college campus media WeChat public platform,take "voice of NCIST" as an example. At present, various functions of college campus media WeChat public platform still need to be developed and utilized,for example, systemic integration with the traditional media (campus radio). This WeChat also has to learn to other outstanding university campus media WeChat public platform, it will usher in a more brilliant development.

\section{Acknowledgements}

This work was financially supported by the Fundamental Research Funds for the Central Universities(3142015055).

\section{References}

[1]GUO Pei-pei. The current political expression of WeChat public platform. [J].New Media,2015(8):46-49(in Chinese).

[2]Chinese Internet data information centre. Tencent: The Data Report of WeChat Platform In 2015.[EB/OL].[2015-01-27]. http://www.199it.com/archives/324845.html

[3] PENG Li-juan. Present situation and the thinking about the official college WeChat public platform. [J]. News Research, 2015(7): 84-86 (in Chinese).

[4]CHE Jia-ning. The research and analysis of college WeChat public platform. [J]. Public Communication of Science \& Technology, 2015(6):125-126.(in Chinese).

[5]CHE Feng. Investigation and analysis of college WeChat public platform. [J]. News Research, 2015(9): 81-82 (in Chinese). 